\title{
Rapid Characterization of Four Species of the Saccharomyces Sensu Stricto Complex According to Mitochondrial DNA Patterns
}

\author{
JOSÉ MANUEL GUILLAMÓN,${ }^{1} \dagger$ ELADIO BARRIO, ${ }^{2}$ TOMÁS HUERTA, ${ }^{1}$ AND AMPARO QUEROL ${ }^{1 *}$ \\ Departamento de Microbiología ${ }^{1}$ and Departamento de Genética, ${ }^{2}$ Facultad de Ciencias Biológicas, \\ Universitat de València, 46100-Burjasot, Valencia, Spain
}

\begin{abstract}
Several strains of the four sibling species of the genus Saccharomyces (S. bayanus, S. cerevisiae, S. paradoxus, and $S$. pastorianus) were characterized by using a rapid and simple method of restriction analysis of mitochondrial DNA. Patterns obtained with four-cutter endonucleases (such as AluI, DdeI, HinfI, and RsaI) made it possible to differentiate each species. $S$. cerevisiae and $S$. paradoxus presented a greater number of large fragments than $S$. pastorianus and $S$. bayanus with all the assay enzymes. With $A l u I$ and $D$ deI, species-specific bands clearly permitted differentiation between $S$. pastorianus and $S$. bayanus. To test the resolution of this method, wild Saccharomyces strains were analyzed. The correct assignment of these strains to a known taxon by this rapid method was confirmed by means of electrophoretic karyotyping.
\end{abstract}

Morphological and physiological characteristics have traditionally provided a wealth of yeast systematic information. This information has been used to establish a series of yeast classification systems $(3,4,16)$. However, none of the various systems is entirely satisfactory, even for the delimitation of species, since most of the criteria used are based on physiological characteristics which are in some cases controlled by single mutable genes $(19,35,40,41)$.

In the 1970s and throughout the 1980s, DNA-DNA hybridization provided genetic information which was useful for determining relatedness among closely related yeast species $(17,35)$. Measurements of nuclear DNA complementarity demonstrated that many species previously described as different according to polymorphic phenotypic characteristics were synonymous $(19,35)$. This was the case for species of the Saccharomyces sensu stricto complex $(44,46)$.

The instability of physiological properties $(40,41)$, analysis of reproductive isolation (26), and DNA-DNA hybridization (45-47) led to the relegation of many previously recognized Saccharomyces sensu stricto species to four taxa: $S$. cerevisiae, $S$. bayanus, $S$. paradoxus, and $S$. pastorianus (for a recent review of the genus Saccharomyces, see reference 3).

Although some authors (47) maintain that most Saccharomyces species can be differentiated only by DNA-DNA hybridization, others have attempted different molecular techniques. These include DNA fingerprinting (5, 31-34, 42), chromosomal DNA profiles $(7,9,14,15,21,27)$, mitochondrial DNA (mtDNA) restriction analysis $(22,48)$, and rRNA and ribosomal DNA (rDNA) sequencing (18) as well as restriction analysis $(13,23-25)$. Until now, only electrophoretic karyotyping, rRNA sequencing and rDNA restriction analysis have proved useful for differentiating Saccharomyces species. However, these techniques are expensive, time-consuming, and complex for use with a large number of strains.

While restriction endonuclease analysis of mtDNA has been used for strain differentiation $(10,22,48)$, it has not been widely used for the differentiation of yeast species, with the

\footnotetext{
* Corresponding author. Mailing address: Departamento de Biotecnología, Instituto de Agroquímica y Tecnología de Alimentos, C.S.I.C., c/Jaime Roig 11, 46010 Valencia, Spain. Phone: 34-6-369-0800. Fax: 34-6-393-0001. Electronic mail address: AmparoQuerol<ebamo@evalsb. geneti.uv.es>.

$\dagger$ Present address: Unitat de Microbiologia, Facultat de Medicina, Universitat Rovira i Virgili, 43201 Reus, Tarragona, Spain.
}

exception of some Candida species (43). The high level of variability observed in restriction analysis, due to length polymorphism, has made it difficult to determine relationships among yeast species (17). Because mtDNA purification is also complex $(11,36)$, its application to taxonomy has been limited to characterizing brewery $(1,22)$ and wine $(8,10,12,39,48)$ strains.

The recent development of a rapid and simple method of yeast mtDNA restriction analysis which does not require previous isolation of mitochondria or purification of mtDNA $(37,38)$ made it possible to characterize a large number of wild yeast strains easily. In the present study, this method has been applied to the identification of strains belonging to species of the genus Saccharomyces sensu stricto.

\section{MATERIALS AND METHODS}

Yeast strains. Twenty-five strains of Saccharomyces species were examined; 10 were obtained from culture collections (Table 1), and the other 15 were wild strains collected from different wines (Table 2).

mtDNA restriction analysis. DNA extraction and determination of mtDNA restriction patterns of the strains were carried out as previously described by Querol et al. $(37,38)$ with the restriction endonucleases $A l u \mathrm{I}, D d e \mathrm{I}, H i n \mathrm{fI}$, and $R s a \mathrm{I}$ (Boehringer Mannheim). Restriction fragments were separated on horizontal 0.8 to $1.2 \%$ agarose slab gels in $0.5 \times \mathrm{TBE}$ buffer (44.5 mM Tris-borate, $1 \mathrm{mM}$ EDTA, $\mathrm{pH} 8$ ). This method requires only $3 \mathrm{~h}$ for the DNA extraction, $2 \mathrm{~h}$ for the endonuclease digestion of the DNAs, and $2 \mathrm{~h}$ for the electrophoretic resolution of the restriction fragments (38).

Chromosomal DNA preparations and pulsed-field electrophoresis. Chromosomal profiles were determined by the contour-clamped homogeneous electric field electrophoresis technique with a CHEF-DRII apparatus (Bio-Rad Laboratories). Chromosomal DNA was prepared in agarose plugs (6) and washed three times in TE buffer $(10 \mathrm{mM}$ Tris- $\mathrm{HCl}, 1 \mathrm{mM}$ EDTA, $\mathrm{pH} 8$ ) at $50^{\circ} \mathrm{C}$ for $30 \mathrm{~min}$ and then once in the same buffer at room temperature for $30 \mathrm{~min}$. Plugs were loaded in $1 \%$ agarose gels in $1 \times \mathrm{TBE}$ buffer, and migration was at $12^{\circ} \mathrm{C}$ and $200 \mathrm{~V}$ with two pulse intervals, $15 \mathrm{~h}$ with $60 \mathrm{~s}$ and $8 \mathrm{~h}$ with $90 \mathrm{~s}$.

Estimates of similarities between electrophoretic patterns. mtDNA restriction electropherograms were scanned and dig- 
TABLE 1. Type and reference strains of Saccharomyces sensu stricto species examined

\begin{tabular}{|c|c|c|c|c|}
\hline \multirow{2}{*}{ Species } & \multicolumn{2}{|c|}{ Strain designation } & \multirow{2}{*}{ Original epithet } & \multirow{2}{*}{ Isolation source } \\
\hline & $\overline{\mathrm{CECT}^{a}}$ & Other $^{b}$ & & \\
\hline \multirow[t]{2}{*}{ S. bayanus Saccardo 1895} & $1941^{\mathrm{T}}$ & CBS 380 & Type of $S$. bayanus & Turbid beer \\
\hline & 1969 & CBS 395 & Type of $S$. uvarum & Currant juice \\
\hline \multirow[t]{3}{*}{ S. cerevisiae Meyen ex Hansen 1883} & $1897^{\mathrm{T}}$ & CBS 1171 & Neotype of $S$. cerevisiae & Beer (top yeast) \\
\hline & 1971 & CBS 1395 & Type of $S$. ellipsoideus & \\
\hline & $-^{c}$ & YGSC X 2180 & Laboratory strain & \\
\hline \multirow[t]{2}{*}{ S. paradoxus Batschinskaya 1914} & $1939^{\mathrm{T}}$ & CBS 432 & Neotype of $S$. paradoxus & Tree exudate \\
\hline & 1972 & UCD51-186 & S. cerevisiae var. tetrasporus & Drosophila sp. \\
\hline \multirow[t]{3}{*}{ S. pastorianus Hansen 1904} & $1320^{\mathrm{T}}$ & CBS 1538 & Neotype of $S$. pastorianus & Hansen's culture, 23 January 1888 \\
\hline & 1940 & & & Beer \\
\hline & 1970 & CBS 1503 & Type of $S$. monacensis & Beer (bottom yeast) \\
\hline
\end{tabular}

${ }^{a}$ CECT, Spanish Type Culture Collection, University of Valencia, Valencia, Spain.

${ }^{\circ}$ CBS, Centraalbureau voor Schimmelcultures, Delft, The Netherlands; UCD, Department of Food Science and Technology, University of California, Davis; YGSC, Yeast Genetics Stock Center, University of California, Berkeley.

$c$, no designation.

itized with a LKB 2202 Ultroscan Laser Densitometer. The similarities between patterns were determined by the fraction of shared bands (Dice coefficient). Clustering was calculated by the unweighted pair group method using arithmetic average linkage (UPGMA method) included in the NTSYS package (Numerical Taxonomy and Multivariate Analysis System, Exeter Publishing Ltd.).

\section{RESULTS}

The mtDNA restriction patterns of the type strains obtained with three of the enzymes are shown in Fig. 1. Well-developed and reproducible mtDNA restriction bands were obtained for all of the strains studied, and the four endonucleases revealed a high level of restriction fragment length polymorphism. When mtDNA was digested with HinfI, each strain exhibited a specific restriction pattern. However, with the other enzymes (AluI, DdeI, or RsaI), generally species-specific restriction fragments were revealed. Restriction patterns of the $S$. cerevi-

TABLE 2. Wild Saccharomyces strains isolated from different wines analyzed in the present study

\begin{tabular}{llll}
\hline $\begin{array}{c}\text { CECT } \\
\text { no. }\end{array}$ & \multicolumn{1}{c}{ Wine region } & \multicolumn{1}{c}{$\begin{array}{c}\text { Original } \\
\text { identification }\end{array}$} & $\begin{array}{c}\text { New } \\
\text { identification } \\
\text { based on this } \\
\text { study }\end{array}$ \\
\hline 1369 & Rioja, Spain & S. pastorianus & S pastorianus \\
1476 & California & S. cerevisiae & S. cerevisiae \\
1477 & Bordeaux, France & S. cerevisiae & S. cerevisiae \\
1483 & Chiva, Spain & S. cerevisiae & S. cerevisiae \\
1484 & Requena, Spain & S. bayanus & S. cerevisiae \\
1732 & Requena, Spain & S. cerevisiae & S. cerevisiae \\
1742 & Requena, Spain & S. chevalier & S. cerevisiae \\
1881 & Jumilla, Spain & S. exiguus & S. cerevisiae \\
1883 & Sanlúcar, Spain & S. oviformis & S. cerevisiae \\
1884 & Campo de Borja, Spain & S. uvarum & S. pastorianus \\
1885 & Valladolid, Spain & S. ellipsoideus & S. pastorianus \\
1887 & Albariño, Spain & S. cerevisiae & S. cerevisiae \\
1890 & Ribeiro, Spain & S. cerevisiae & S. cerevisiae \\
1891 & Alicante, Spain & S. cerevisiae & S. cerevisiae \\
1892 & Alicante, Spain & S. cerevisiae & S. cerevisiae \\
\hline
\end{tabular}

" CECT, Spanish Type Culture Collection, University of Valencia, Valencia, Spain. siae and $S$. paradoxus strains obtained with these enzymes showed a greater number of large fragments $(>5 \mathrm{~kb})$ than those of the $S$. pastorianus and $S$. bayanus strains. In the case of $A l u \mathrm{I}$ and particularly with $D d e \mathrm{I}$, species-specific bands (indicated in Fig. 1 by arrows) clearly permitted differentiation between these last two species.

When the method of identification based on mtDNA restriction analysis was applied to wild strains, the discriminatory power of the technique was confirmed. Restriction patterns of 9 of the 15 wild strains analyzed are shown in Fig. 2. A very close restriction pattern similarity between the wild strains and their respective standards is evident, despite the variable geographic origins of the strains. Thus, seven of the natural wine strains analyzed exhibited a typical $S$. cerevisiae mitochondrial pattern similar to those of the reference strains (cf. Fig. 1 and 2).

Three additional strains, 1369 and 1885 (Fig. 2), and 1884 (data not shown) can be ascribed to a species according to their restriction patterns. These strains (cf. Fig. 1 and 2) present $D d e \mathrm{I}$ and $A l u \mathrm{I}$ patterns similar to those of the standard $S$. pastorianus strains $1320^{\mathrm{T}}$ and 1940 (Fig. 1) and 1970 (data not shown). None of the wild strains showed a pattern similar to those of the $S$. bayanus standards.

To assess the reliability of this method and its potential use in the differentiation and identification of strains belonging to the different Saccharomyces sensu stricto species, an analysis of the chromosomal profiles of these strains as previously characterized by other authors $(21,27)$ was carried out.

The electrophoretic karyotypes of type and reference strains (Table 1) are shown in Fig. 3. Interspecific and intraspecific differences in the numbers and mobilities of the bands were seen. The number of bands was 12 or 13 for $S$. cerevisiae, 14 for $S$. paradoxus, 15 or 17 for $S$. bayanus, and 17 for $S$. pastorianus.

Interspecific karyotypic differences in the higher-molecularweight bands $(>900 \mathrm{~kb})$ are seen. In that region, the $S$. cerevisiae strains $\left(1897^{\mathrm{T}}\right.$ and 1971) gave three bands corresponding, from higher to lower molecular weights, to the doublets formed by chromosomes IV and XII, XV and VII, and XVI and XIII (15). $S$. paradoxus gave a similar profile, differing only in the separation of chromosomes XIII and XVI, as well as V and VIII (27).

In the high-molecular-weight region, the chromosomal patterns of $S$. pastorianus and $S$. bayanus were quite similar, but 

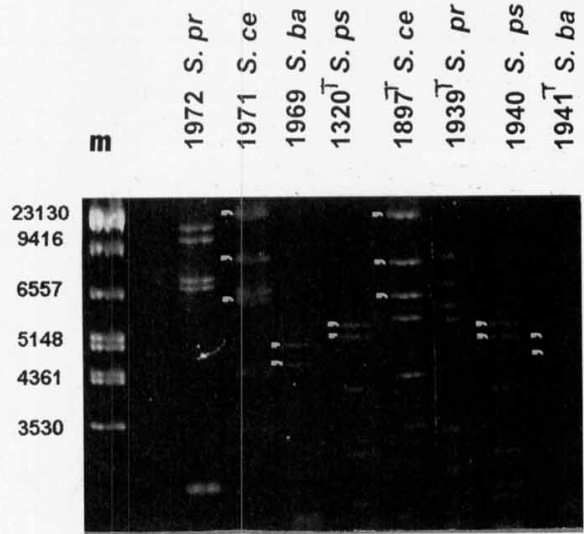

Alu I

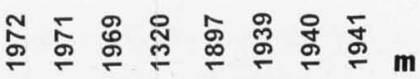

Dde I

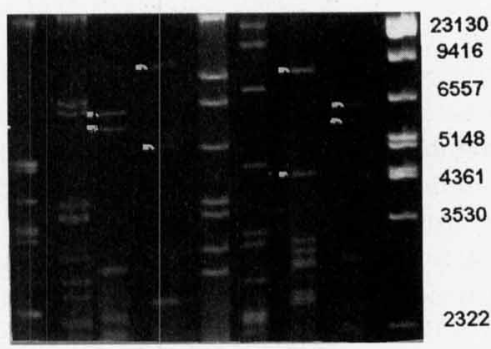

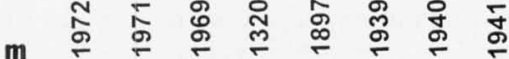

Hinf I

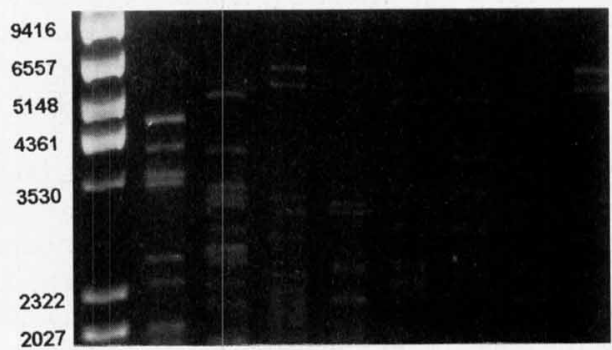

FIG. 1. mtDNA restriction analysis of type and reference strains of Saccharomyces sensu stricto species with the restriction endonucleases AluI, DdeI, and HinfI. White arrows indicate species-specific bands. Lanes $\mathrm{m}$, a mixture of lambda DNA digested with HindIII and $H$ indIII-EcoRI used as size markers. Sizes in kilobases are indicated on the left or right. Abbreviations: S. ce, S. cerevisiae; S. ba, S. bayanus; S. pr, S. paradoxus; S. ps, S. pastorianus.

they were very different from those of $S$. cerevisiae and $S$. paradoxus, since two or three additional bands can be observed. These extra bands could have arisen from the resolution of some of the doublets present in $S$. cerevisiae, because of chromosomal size differences or the existence of different copies of some of the chromosomes in these species $(29,30)$.

Intraspecific chromosomal polymorphisms were observed in the region corresponding to the smallest chromosomes $(<900$ $\mathrm{kb}$ ) of the karyotypes shown in Fig. 3. This is due to the easy electrophoretic detection of many deletions, insertions, or translocations of DNA fragments longer than $10 \mathrm{~kb}$, giving specific chromosomal patterns for each strain.

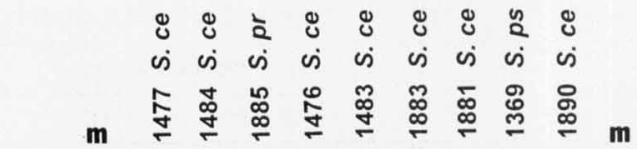

Alu I

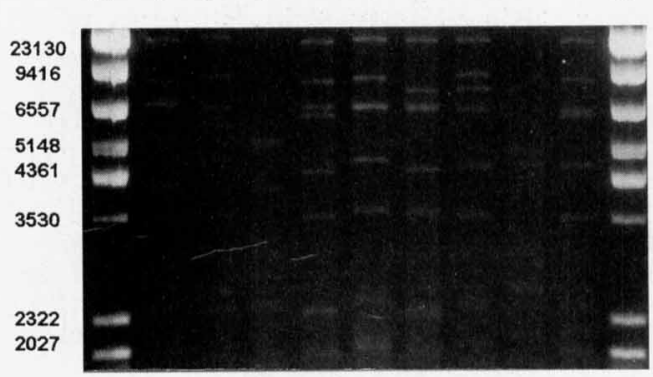

DdeI
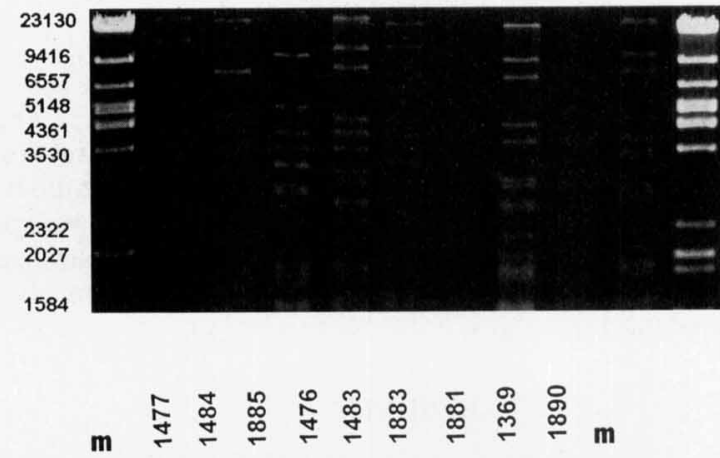

Hinf I

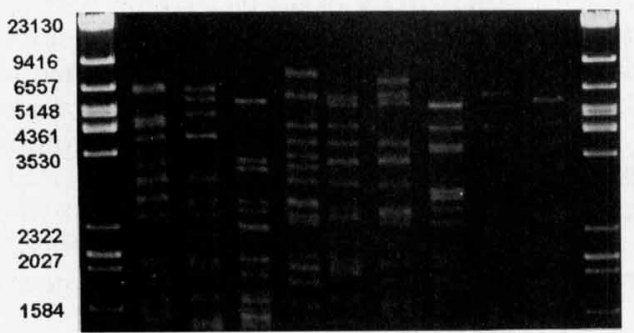

FIG. 2. mtDNA restriction analysis of wild yeast strains with the restriction endonucleases $A l u \mathrm{I}, D d e \mathrm{I}$, and HinfI. Size markers and abbreviations are as in Fig. 1.

Although each strain exhibited a specific profile in the region of low molecular weight, general patterns determined by species-specific bands were observed in the region of high molecular weight for $S$. cerevisiae and $S$. paradoxus but not for S. bayanus or S. pastorianus, which had similar, but not identical, patterns.

Electrophoretic karyotypes of five of the wine strains are shown in Fig. 4. The 12 strains that showed an S. cerevisiae mtDNA restriction pattern (Table 2) showed the typical $S$. cerevisiae chromosomal profile in the high-molecular-weight region, characterized by the presence of three doublets formed by the largest chromosomes, IV-XII, XV-VII, and XVI-XIII, and the doublet formed by chromosomes $\mathrm{V}$ and VIII. The three strains, characterized as $S$. pastorianus according to their mtDNA patterns, did not present the typical $S$. cerevisiae chromosome profile in the high-molecular-weight region of the karyotypes. Thus, patterns exhibited by strains 1884 and 1885 

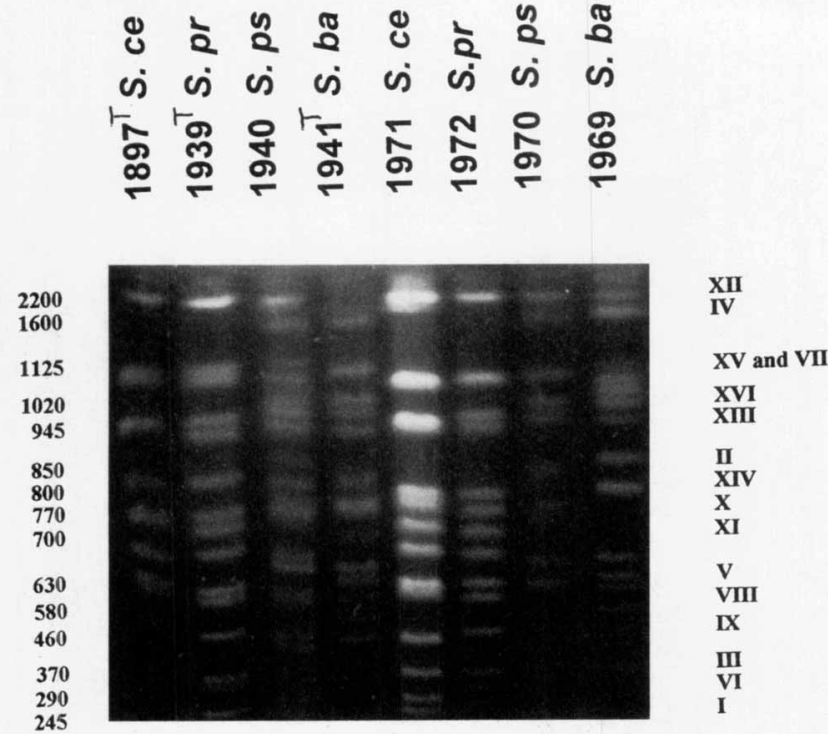

FIG. 3. Chromosome profiles of the type and reference strains of Saccharomyces sensu stricto species as detected after chromosome electrophoresis on agarose gels by the contour-clamped homogeneous electric field method. Sizes in kilobases (left) and mobilities (right) of the chromosomes from strain YNN295 (Bio-Rad), used as markers, are indicated. Abbreviations for the species names are as in Fig. 1.

(Fig. 4) and 1369 (data not shown) were very similar to those of the reference strains of $S$. pastorianus (1940 and 1970) and S. bayanus $\left(1941^{\mathrm{T}}\right.$ and 1969$)$.

It should be noted that the application of this technique also permits the identification of each strain from its specific chromosomal profile. As can be seen in Fig. 4, the most important intraspecific differences are observed in the zone where the smallest chromosomes (I, VI, III, and IX) are resolved, as in the reference and type strains (Fig. 3).

To confirm quantitatively the existence of species-specific patterns, we performed a cluster analysis of similarities among restriction patterns of the 25 strains studied, on the basis of the fraction of shared fragments (Table 3 ). The resulting phenogram from the cluster analysis by the UPGMA method (see reference 28 , p. 293-298) is depicted in Fig. 5.

The phenogram shows the relatedness among mitochondrial restriction patterns of strains belonging to the same species. All $S$. cerevisiae strains are clustered in one group. Within this group, most of the wine strains are grouped together. Closely related to this group of strains are the two $S$. paradoxus strains $\left(1939^{T}\right.$ and 1972), which appear on two different branches sharing common nodes with those branches connecting $S$. cerevisiae strains.

The type strains of $S$. bayanus and $S$. pastorianus are included in two different, but closely related, clusters. The wine strains 1369,1884 , and 1885 are grouped within the $S$. pastorianus cluster together with the three reference $S$. pastorianus strains $\left(1320^{\mathrm{T}}, 1940\right.$, and 1970$)$.

\section{DISCUSSION}

In recent years, rRNA and rDNA sequencing or restriction analysis have been used to determine phylogenetic relationships among yeast species (18). Kurtzman and Robnett (20) determined the phylogenetic relationships among species of several yeast genera, including the currently recognized 10 species of the genus Saccharomyces $(3,16)$, on the basis of the
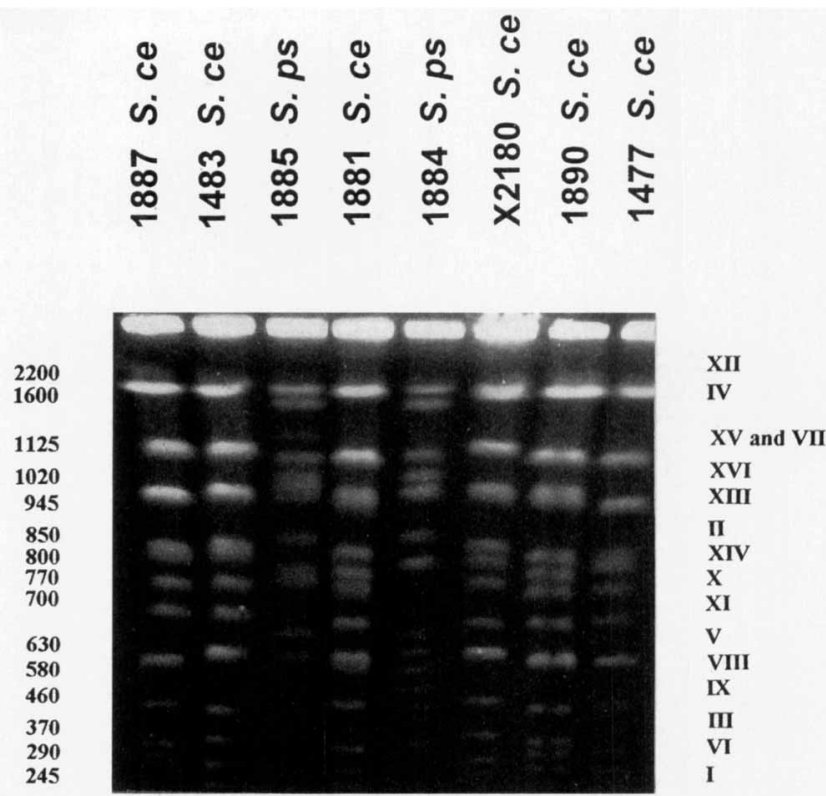

FIG. 4. Chromosome profiles of wild yeast strains as detected after chromosome electrophoresis on agarose gels by the contour-clamped homogeneous electric field method. Sizes in kilobases (left) and mobilities (right) of the chromosomes from strain YNN295 (Bio-Rad), used as markers, are indicated. Abbreviations for the species names are as in Fig. 1

small (18S) and large (25S) rRNA sequences of these species. However, only 12 nucleotide sites were found to be variable when the 900 nucleotide sequences from the species of the Saccharomyces sensu stricto complex were compared. Furthermore, the 900-base sequences from $S$. pastorianus and $S$. bayanus were identical, and those from $S$. cerevisiae and $S$. paradoxus differed in only five nucleotides. rDNA restriction analysis from PCR-amplified fragments $(13,23-25)$ has also been used recently to differentiate between strains belonging to $S$. cerevisiae, $S$. bayanus, and $S$. pastorianus.

The analysis of rDNA sequence polymorphism has made it possible to differentiate between some of the species of the Saccharomyces sensu stricto complex, but is not informative about recent evolution. For this purpose, other genome regions or other genomes (e.g., mtDNA) should be considered.

Since the first orthogonal-field-alternation gel electrophoresis karyotyping by Carle and Olson (6), pulsed-field electrophoresis and probe hybridizations have made it possible to separate and characterize the 16 chromosomes of $S$. cerevisiae. This technique has been applied to many yeast species $(14,15)$, and the comparison of the chromosomal profiles between and within related species has shown a high level of polymorphism. These polymorphisms are due to deletions, insertions, and translocations that are long enough to be detectable electrophoretically. They are mainly observed in the small chromosomes, in which changes in mobility are easily detected.

The taxonomic usefulness of the electrophoretic karyotyping of yeasts has been widely demonstrated, not only to identify or to determine genetic homologies among different species (14, $15,21,27,50)$ but also to characterize different commercial $(39,48)$ or wild $(37,38,49)$ strains. However, the technique is rather complex and time-consuming.

The development of a rapid and simple method of yeast mtDNA restriction analysis in our laboratory $(37,38)$ allows 


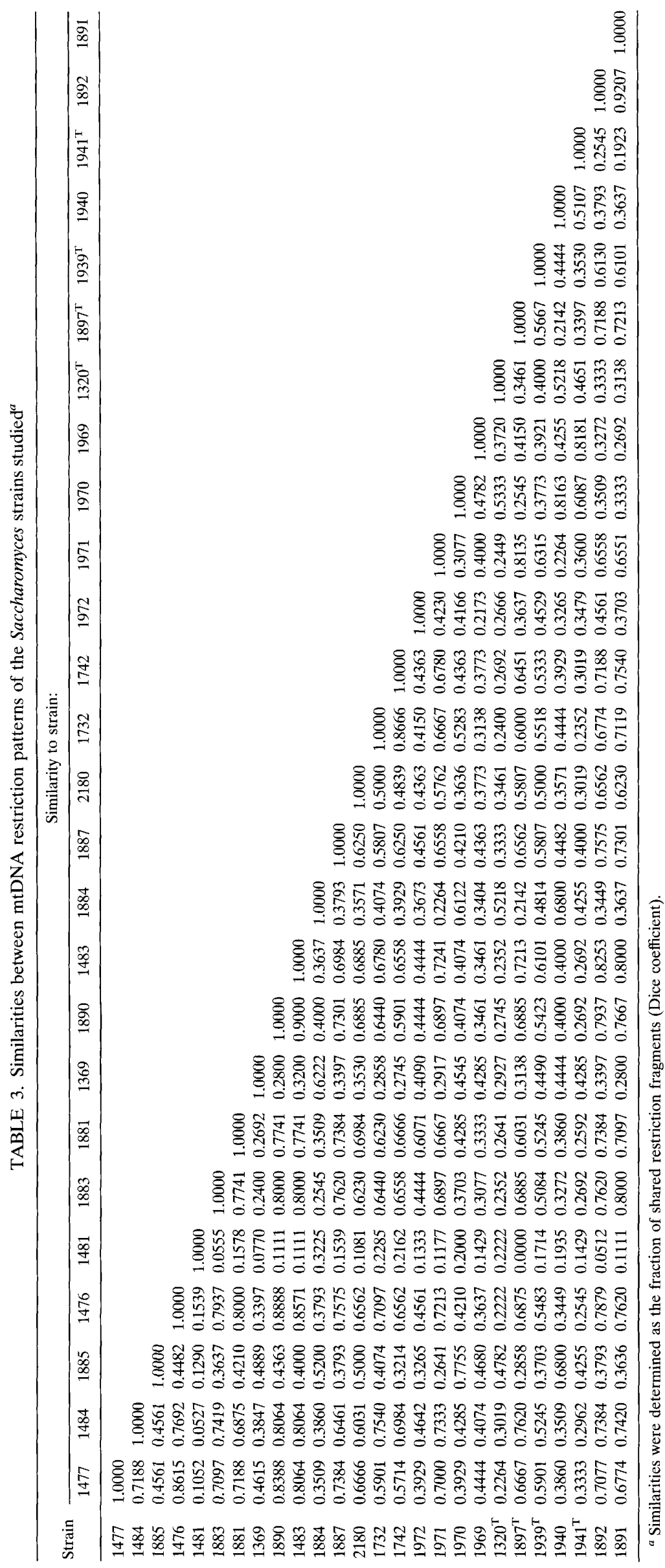




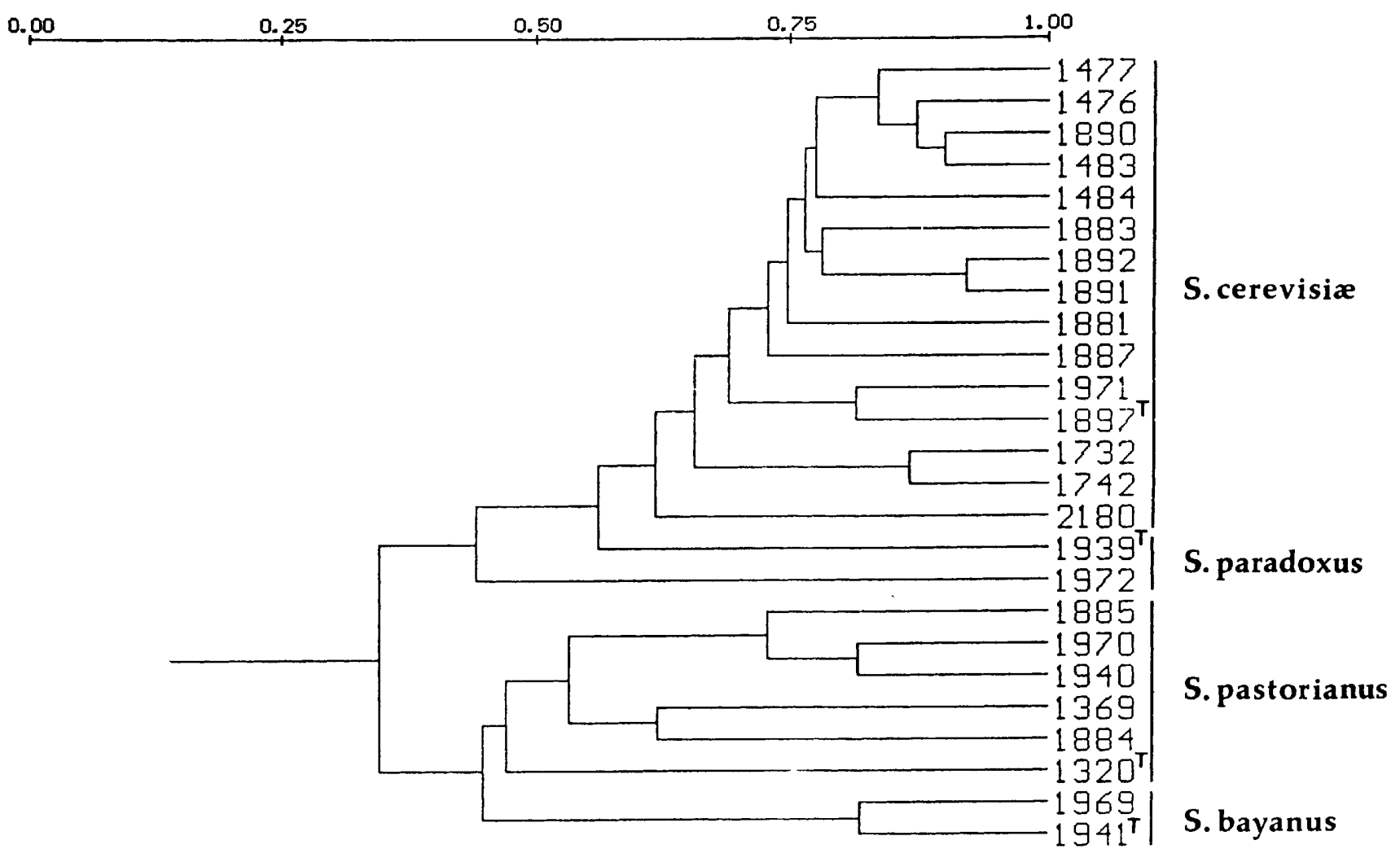

FIG. 5. Dendrogram obtained by the UPGMA method, using the similarity between mtDNA restriction patterns (measured as the Dice coefficient or fraction of shared restriction bands) of the reference and wild Saccharomyces strains analyzed.

easy characterization of a large number of wild yeast strains. To determine if species-specific mtDNA restriction patterns exist, this method was applied to reference and wild strains.

Although the method used here is valuable for taxonomic purposes, its phylogenetic value is limited because of difficulties in estimating DNA divergences from restriction analysis by the method of Nei (28) as a result of the failure of its assumptions. As a consequence of the variability in length observed among yeast mitochondrial genomes, comigrating nonhomologous DNA fragments could be indistinguishable, and homologous DNA fragments could present different electrophoretic mobilities due to insertions or deletions.

However, the cluster analysis of the similarities between yeast mitochondrial restriction patterns is associated with taxonomic position as shown by electrophoretic karyotyping, geographic origin, and ecology of the strains. This association shows the mitochondrial genome to be a valuable marker of the evolution of the species of the Saccharomyces sensu stricto complex at both inter- and intraspecific levels.

According to the present study, if the postulated hybrid origin of $S$. pastorianus from the cross between $S$. cerevisiae and $S$. bayanus $(30,46)$ is true, the mitochondrial genome donor may have been $S$. bayanus on the basis of the similarity of their mtDNA restriction patterns.

The association between chromosomal and mtDNA patterns can be explained by the widespread occurrence of asexual reproduction in these Saccharomyces sensu stricto species (2).

\section{ACKNOWLEDGMENTS}

We thank J. A. Barnett for fruitful discussion and revision of the manuscript and two anonymous reviewers for constructive criticism on an early version of the manuscript.
This work was supported by grant ALI90-0949 from Comisión Interministerial de Ciencia y Tecnología, Spain.

\section{REFERENCES}

1. Aiglé, M., D. Erbs, and M. Moll. 1984. Some molecular structures in the genome of lager brewing yeast. Am. Soc. Brew. Chem. 42:1-7.

2. Bakalinsky, A. T., and R. Snow. 1990. The chromosomal constitution of wine strains of Saccharomyces cerevisiae. Yeast 6:367-382.

3. Barnett, J. A. 1992. The taxonomy of the genus Saccharomyces Meyen ex Reess: a short review for nontaxonomists. Yeast 8:1-23.

4. Barnett, J. A., R. W. Payne, and D. Yarrow. 1990. Yeasts: characteristics and identification, 2nd ed. Cambridge University Press, Cambridge.

5. Braus, G., R. Furter, F. Prantl, P. Niederberg, and R. Hütter. 1985. Arrangement of genes TRP1 and TRP3 of S. cerevisiae strains. Arch. Microbiol. 142:383-388.

6. Carle, G. F., and M. V. Olson. 1985. An electrophoretic karyotype for yeast. Proc. Natl. Acad. Sci. USA 82:3756-3760.

7. Casey, G. P., W. Xiao, and G. H. Rank. 1988. Application of pulsed field chromosome electrophoresis in the study of chromosome XIII and electrophoretic karyotype of industrial strains of Saccharomyces yeasts. J. Inst. Brew. 94:239-243.

8. Degré, R., D. Y. Thomas, J. Ash, K. Mailhiot, A. Morin, and C. Dubord. 1989. Wine yeast strain identification. Am. J. Enol. Vitic. 40:309-315.

9. De Jonge, P., C. M. De Jonge, R. Meijers, R. Steemsa, and W. A. Scheffers. 1986. Orthogonal-field-alternation gel electrophoretic banding patterns from yeasts. Yeast 2:193-204.

10. Dubourdieu, D., A. Sokol, J. Zucca, P. Thalouarn, A. Datte, and M. Aiglé. 1987. Identification des souches de levures isolées de vins par l'analyse de leur ADN mitochondrial. Connaiss. Vigne Vin. 21:267-278.

11. Gargouri, A. 1989. A rapid and simple method for extraction of yeast mitochondrial DNA. Curr. Genet. 15:235-237. 
12. Hallet, J. N., B. Craneguy, J. Zucca, and A. Poulard. 1988. Caractérisation de différentes souches industrielles de levures oenologiques par les profils de restriction de leur ADN mitochondrial. Prog. Agric. Vitic. 105:328-333.

13. Huffman, J. L., F. I. Molina, and S.-C. Jong. 1992. Authentication of ATCC strains in the Saccharomyces cerevisiae complex by PCR fingerprinting. Exp. Mycol. 16:316-319.

14. Johnston, J. R., C. R. Contopoulou, and R. K. Mortimer. 1988. Karyotyping of yeast strains of several genera by field inversion gel electrophoresis. Yeast 4:191-198.

15. Johnston, J. R., and R. K. Mortimer. 1986. Electrophoretic karyotyping of laboratory and commercial strains of Saccharomyces and other yeasts. Int. J. Syst. Bacteriol. 36:569-572.

16. Kreger-van Rij, N. J. W. (ed.). 1984. The yeasts: a taxonomic study, 3rd ed. Elsevier Science Publishers B. V., Amsterdam.

17. Kurtzman, C. P. 1987. Prediction of biological relatedness among yeasts from comparisons of nuclear DNA complementarity. Stud. Mycol. 30:459-468.

18. Kurtzman, C. P. 1992. rRNA sequence comparisons for assessing phylogenetic relationships among yeasts. Int. J. Syst. Bacteriol. 42:1-6.

19. Kurtzman, C. P., and H. J. Phaff. 1987. Molecular taxonomy, p. 63-94. In A. H. Rose and J. S. Harrison (ed.), The yeasts, vol. 1. Biology of yeasts. Academic Press, London.

20. Kurtzman, C. P., and C. J. Robnett. 1991. Phylogenetic relationships among species of Saccharomyces, Schizosaccharomyces, Debaryomyces and Schwanniomyces determined from partial ribosomal RNA sequences. Yeast 7:61-72.

21. L'Hote, H., S. Dequin, and F. Boutelet. 1988. Identification of some chromosomes of the brewing yeast Saccharomyces uvarum. FEMS Microbiol. Lett. 52:219-224.

22. Lee, S. Y., and F. B. Knudsen. 1985. Differentiation of brewery yeast strains by restriction endonuclease analysis of their mitochondrial DNA. J. Inst. Brew. 91:169-173.

23. Molina, F. I., T. Inoue, and S. C. Jong. 1992. Ribosomal DNA restriction analysis reveals genetic heterogeneity in Saccharomyces cerevisiae Meyen ex Hansen. Int. J. Syst. Bacteriol. 42:499-502.

24. Molina, F. I., T. Inoue, and S. C. Jong. 1992. Restriction polymorphisms in the internal transcribed spacers and 5.8S rDNA of Saccharomyces. Curr. Microbiol. 25:251-255.

25. Molina, F. I., S. C. Jong, and J. L. Huffman. 1993. PCR amplification of the $3^{\prime}$ external transcribed and intergenic spacers of the ribosomal DNA repeat unit in three species of Saccharomyces. FEMS Microbiol. Lett. 108:259-264.

26. Naumov, G. I. 1987. Genetic basis for classification and identification of the ascomycetous yeasts. Stud. Mycol. 30:469-475.

27. Naumov, G. I., E. S. Naumova, R. A. Lantto, E. J. Louis, and M. Korhola. 1992. Genetic homology between Saccharomyces cerevisiae and its sibling species $S$. paradoxus and $S$. bayanus: electrophoretic karyotypes. Yeast 8:599-612.

28. Nei, M. 1987. Molecular evolutionary genetics. Columbia University Press, New York.

29. Nilsson-Tillgren, T., C. Gjermansen, M. C. Kielland-Brandt, J. G. L. Petersen, and S. Holmberg. 1981. Analysis of chromosome $\mathrm{V}$ and the $I L V I$ gene from Saccharomyces carlsbergensis. Carlsberg Res. Commun. 46:65-76.

30. Nilsson-Tillgren, T., M. C. Kielland-Brandt, S. Holmberg, J. G. L. Petersen, and C. Gjermansen. 1983. Is lager yeast a species hybrid? Utilization of intrinsic genetic variation in breeding, $\mathrm{p}$. 143-147. Proc. IV Int. Symp. Genet. Ind. Microorg., Kyoto, Japan, 1983.

31. Pedersen, M. B. 1983. DNA sequence polymorphisms in the genus Saccharomyces. I. Comparison of the HIS4 and ribosomal RNA genes in lager strains, ale strains and various species. Carlsberg Res. Commun. 48:485-503.
32. Pedersen, M. B. 1985. DNA sequence polymorphisms in the genus Saccharomyces. II. Analysis of the genes RDN1, HIS4, LEU2 and Ty transposable elements in Carlsberg, Tuborg and Bavarian brewing strains. Carlsberg Res. Commun. 50:263-272.

33. Pedersen, M. B. 1986. DNA sequence polymorphisms in the genus Saccharomyces. III. Restriction endonuclease fragment patterns of chromosomal regions in brewing and other yeast strains. Carlsberg Res. Commun. 51:163-183.

34. Pedersen, M. B. 1986. DNA sequence polymorphisms in the genus Saccharomyces. IV. Homologous chromosomes III of Saccharomyces bayanus, S. carlsbergensis, and $S$. uvarum. Carlsberg Res. Commun. 51:185-202.

35. Price, C. W., G. B. Fuson, and H. J. Phaff. 1978. Genome comparison in yeast systematics: delimitation of species within genera Schwanniomyces, Saccharomyces, Debaryomyces, and Pichia. Microbiol. Rev. 42:161-193.

36. Querol, A., and E. Barrio. 1990. A rapid and simple method for the preparation of yeast mitochondrial DNA. Nucleic Acids Res. 18:1657.

37. Querol, A., E. Barrio, T. Huerta, and D. Ramón. 1992. Molecular monitoring of wine fermentations conducted by active dry yeast strains. Appl. Environ. Microbiol. 58:2948-2953.

38. Querol, A., E. Barrio, and D. Ramón. 1992. A comparative study of different methods of yeast strain characterization. Syst. Appl. Microbiol. 15:439-446.

39. Querol, A., T. Huerta, E. Barrio, and D. Ramón. 1992. Strain for use as dry yeast in fermentation of Alicante wines: selection and DNA patterns. J. Food Sci. 57:183-185.

40. Scheda, R., and D. Yarrow. 1966. The instability of physiological properties used as criteria in the taxonomy of yeasts. Arch. Mikrobiol. 55:209-225.

41. Scheda, R., and D. Yarrow. 1968. Variation in the fermentation pattern of some Saccharomyces species. Arch. Mikrobiol. 61:310316.

42. Seehaus, T., R. Rodicio, J. Heinisch, H. D. Aguilera, and F. K. Zimmermann. 1985. Specific gene probes as tools in yeast taxonomy. Curr. Genet. 10:103-110.

43. Su, C. S., and S. A. Meyer. 1991. Characterization of mitochondrial DNA in various Candida species. Isolation, restriction endonuclease analysis, size, and base composition. Int. J. Syst. Bacteriol. 41:6-14.

44. Van der Walt, J. P. 1970. Saccharomyces Meyen emend. Reess, p. 555-718. In J. Lodder (ed.), The yeasts: a taxonomic study. Elsevier/North-Holland Publishing Co., Amsterdam.

45. Vaughan Martini, A. 1989. Saccharomyces paradoxus comb. nov., a newly separated species of the Saccharomyces sensu stricto complex based upon nDNA/nDNA homologies. Syst. Appl. Microbiol. 12:179-182.

46. Vaughan Martini, A., and C. P. Kurtzman. 1985. Deoxyribonucleic acid relatedness among species of the genus Saccharomyces sensu stricto. Int. J. Syst. Bacteriol. 35:508-511.

47. Vaughan Martini, A., and A. Martini. 1987. Three newly delimited species of Saccharomyces sensu stricto. Antonie van Leeuwenhoek 53:77-84.

48. Vezinhet, F., B. Blondin, and J. N. Hallet. 1990. Chromosomal DNA patterns and mitochondrial DNA polymorphism as tools for identification of enological strains of Saccharomyces cerevisiae. Appl. Microbiol. Biotechnol. 32:568-571.

49. Vezinhet, F., J. N. Hallet, M. Valade, and A. Poulard. 1992. Ecological survey of wine yeast strains by molecular methods of identification. Am. J. Enol. Vitic. 43:83-86.

50. Viljoen, B. C., J. L. F. Kock, and D. J. Coetzee. 1988. Orthogonalfield-alternation gel electrophoresis banding patterns of some asporogenous yeasts and their respective ascosporogenous states. Syst. Appl. Microbiol. 10:228-230. 